\title{
SYNTHESIS OF ZEOLITE FROM INORGANIC WASTES
}

\author{
Veeresh P. Mallapur ${ }^{1}$, John U. Kennedy Oubagaranadin ${ }^{2}$, Satish S. Lature ${ }^{3}$ \\ ${ }^{1,2}$ Department of Ceramic \& Cement Technology, ${ }^{3}$ Department of Physics, PDA College of Engineering, Gulbarga \\ 585102, Karnataka, INDIA: \\ veereshpmallapur@gmail.com,ju_kennedy@yahoo.co.in,satish_lature@yahoo.co.in
}

\begin{abstract}
The synthesis of zeolite in forms suitable for industrial applications is of great importance, mainly as ion exchange material, molecular sieves, adsorbents and catalyst. In the present investigation an effort has been made to synthesize zeolite from glaze free ceramic (inorganic) wastes (porcelain bodies) such as broken stoneware pipe and washbasin. Porcelain mainly is composed of amorphous glass phase and crystalline phases such as quartz and mullite. Most of the amorphous and crystalline phases are converted into soluble phases by alkali fusion and transformed into zeolite crystals with high specific area and unique micro-pores. The synthesized zeolites were characterized using X-ray powder diffraction.
\end{abstract}

Keywords: Zeolite, porcelain, clay

\section{INTRODUCTION}

Zeolites are microporous, aluminosilicate minerals commonly used as commercial adsorbents. There are a group of more than 40 crystalline hydrated alumino silicate minerals. Their structure is based on a three dimensional network of an aluminum and silicon tetrahedral linked by shared oxygen atoms. Due to specific pore sizes and large surface areas, zeolites can be used in various applications as molecular sieves, adsorbents, catalysts etc. [1]. Several researchers reported the synthesis of zeolites from a wide variety of starting materials containing high amounts of $\mathrm{Si}$ and $\mathrm{Al}$, e.g., kaolin, high-silica bauxite, halloysite, interstratified illitesmectite, montmorillonite, bentonite, and incinerated ash. [29].

In ceramic industries defected and unsold fired products are usually considered as waste materials and they are discarded as wastes and some of them are used as artificial aggregate for cement production or for other minor applications [10]. The remaining ceramic wastes are deposited in landfill sites. Such deposits may cause social and environmental problems. In the present work an effort has been made to develop zeolite material from waste stoneware pipes and broken washbasins using alkali fusion method.

\section{EXPERIMENTAL}

\subsection{Materials Used}

Waste porcelain was ground to a powder (particle size $<1 \mathrm{~mm}$ ) by grinding in a ball mill and was then washed with distilled water. The porcelain (broken stoneware and washbasin) mainly comprised $\mathrm{SiO}_{2}$ (major constituent) with rest amount of $\mathrm{Al}_{2} \mathrm{O}_{3}, \mathrm{Na}_{2} \mathrm{O}, \mathrm{K}_{2} \mathrm{O}, \mathrm{MgO}, \mathrm{CaO}, \mathrm{Fe}_{2} \mathrm{O}_{3}$, and $\mathrm{ZnO}$.

\subsection{Zeolite Synthesis}

Zeolite synthesis was carried out as shown in Fig. 1 below:

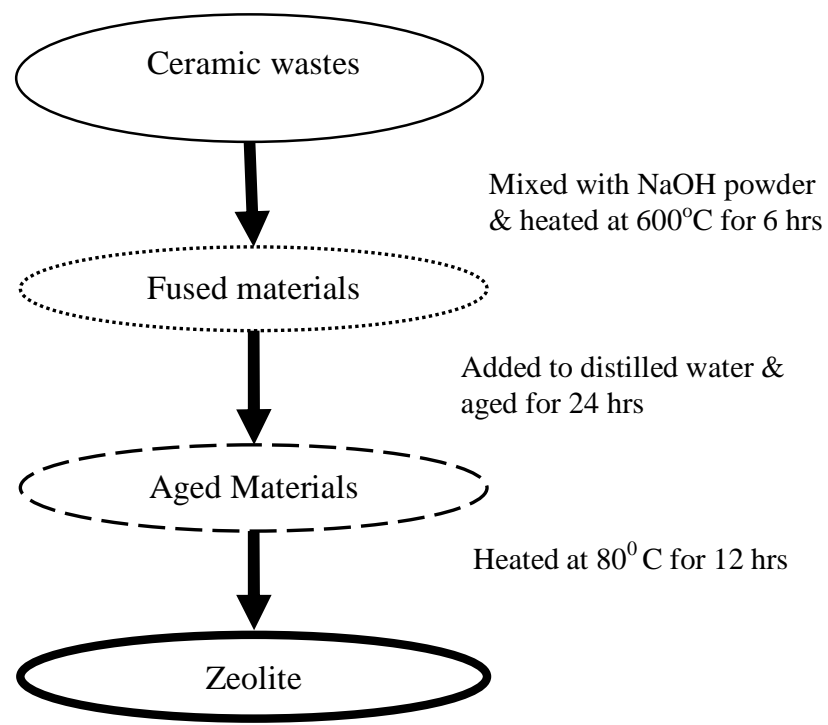

Figure 1: Flow diagram for zeolite synthesis

Ten grams of glaze free powdered ceramic wastes was mixed with $12 \mathrm{~g}$ of $\mathrm{NaOH}$ powder. It was ground to obtain a homogeneous mixture. This mixture was heated in a nickel crucible in air at $600^{\circ} \mathrm{C}$ for $6 \mathrm{~h}$. The resultant material was cooled to room temperature and ground again to obtain the fused material. Fused material $(0.5 \mathrm{~g})$ was added to $2 \mathrm{ml}$ of distilled water in a $10 \mathrm{ml}$ tube made of polymethylpentene. An 
aging process followed this, with vigorous agitation in a reciprocal shaker at room temperature to obtain the aged material. After agitation for $24 \mathrm{~h}$, the aged material was heated in a water bath at $80^{\circ} \mathrm{C}$ for $12 \mathrm{~h}$ to obtain the product. The aged material and product were filtered, washed with distilled water, and dried in an air oven at $60^{\circ} \mathrm{C}$ overnight. Characterization of raw material, fused material, aged material and product was carried out by X-ray powder diffraction (XRD).

\section{RESULTS AND DISCUSSION}

In this work two porcelain material, stone ware (SW) and washbasin (WB) wastes were used to synthesis zeolite by alkali fusion method. Fig. 2 shows the XRD patterns obtained for the raw material $(\mathrm{R})$, fused / treated material $(\mathrm{T})$, aged material (A), and product zeolite (Z). The raw material comprised an amorphous glass phase and crystalline quartz.
After fusion, most of the phases in the raw material were converted into soluble sodium silicate and then converted to amorphous material through agitation for $24 \mathrm{~h}$. Zeolite-X phase was detected in the product.

Fig. 2 shows the XRD patterns of raw material, fused material / treated material, aged material and the product zeolite. The XRD of the raw material indicates that stoneware and washbasin mainly consisted of silica hexagonal phase (matched with JCPDS No. 861628). During fusion process, silica reacts with sodium hydroxide giving raise to sodium silicate (matched with JCPDS No. 740085), which is soluble. The aged material was amorphous with some residual sodium in it. Finally when the product was heated to $80^{\circ} \mathrm{C}$ a zeolite phase with crystal system BCC was formed (matched with JCPDS No. 2467 and ICSD No. 073930) with space group $1 \mathrm{~m} 3 \mathrm{~m}$ and having a lattice constant $4.29 \AA$.

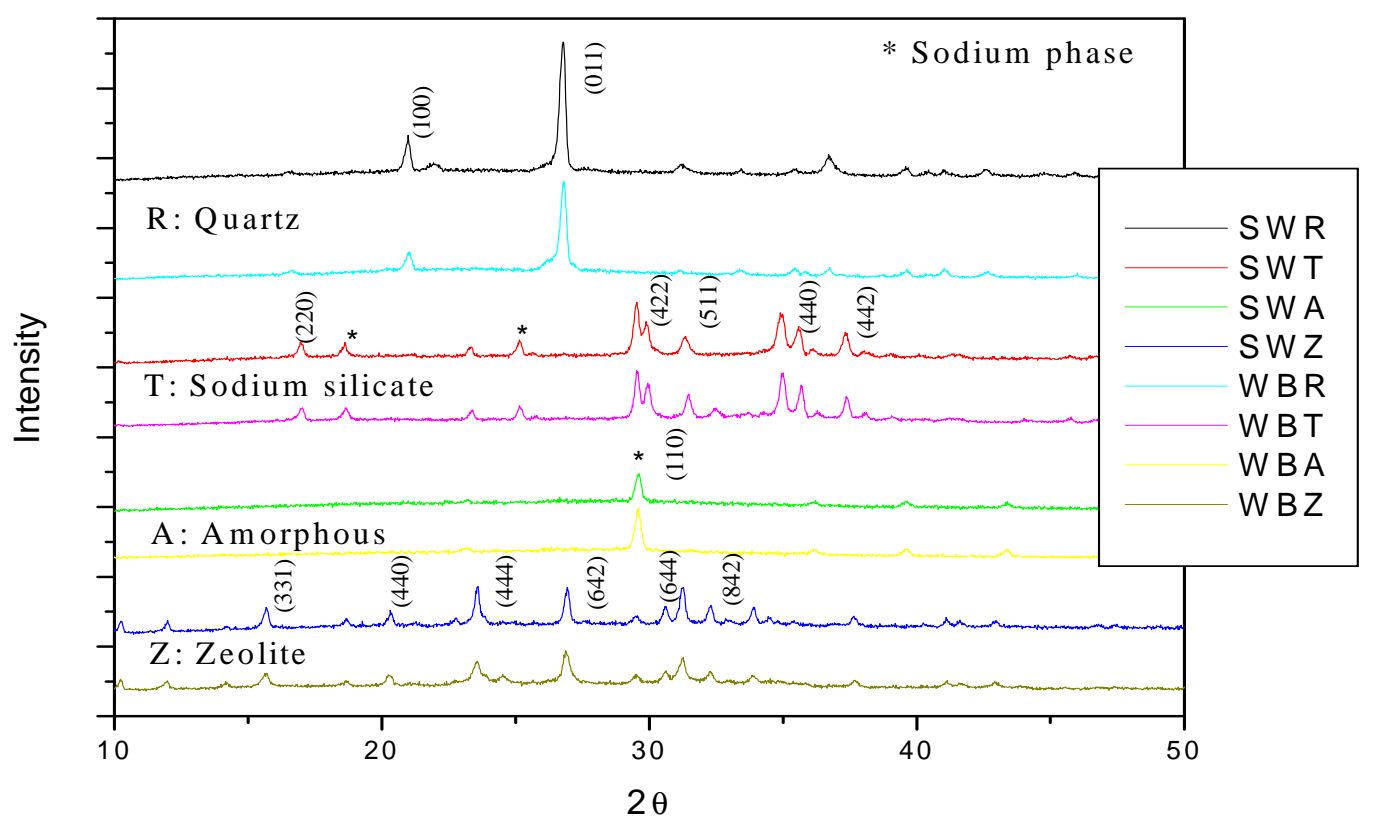

Fig.2: XRD patterns of 1) Raw material (R) 2) Treated (Fused) material (T) 3) Aged material (A) and 4) Zeolite(Z)

SWR: Stoneware raw, SWT: Stoneware treated, SWA: Stoneware aged, SWZ: Stoneware zeolite, WBR: Washbasin raw, WBT: Washbasin treated, WBA: Washbasin aged, WBZ: Washbasin zeolite

\section{CONCLUSIONS}

An attempt has been made in this work to convert waste porcelain bodies such as stoneware and washbasin into crystalline zeolite using a single step alkali fusion method.
The synthesized product is a highly valued zeolite product that could be used as a molecular sieve or as an adsorbent. SEM and pore-size studies can further be carried out for the synthesized zeolites (SWZ \& WBZ). 


\section{ACKNOWLEDGEMENTS}

The authors thank Dr. G.H. Jadhav, Professor, Dept. of Physics, Shri. Chhatrapati Shivaji College, Omerga, Maharashtra, for his help in XRD analysis of the samples

\section{REFERENCES}

[1] R.M. Barrer, "Zeolites and Clay Minerals as Sorbents and Molecular Sieves", Academic Press, London, 1978

[2] R.M. Barrer, R. Beaumont and C. Colella, "Chemistry of soil minerals, Part XIV, Action of some basic solution on metakaolinite and kaolinite", Journal of the Chemical Society, Dalton Transaction, 1974, pp 934

[3] R. Ruiz, C. Banco, C. Pesquera, F. Gonzalez, I. Benito and J.L. Lopez, "Zeolitization of a bentonite and its application to the removal of ammonium ion from waste water”, Applied Clay Science , Vol. 12 , 1997, pp. 73.

[4] A. Baccouche, E. Srasra and M.E. Maaoui, "Preparation of Na-P1 and sodalite octahydrate zeolites from interstratified illite-smectite", Applied Clay Science, Vol. 13, 1998, pp. 255-273

[5] A. F. Gualtieri, "Synthesis of sodium zeolites from a natural halloysite", Physics and Chemistry of Minerals, Vol. 28, 2001, pp. 719

[6] D. Boukadir, N. Bettahar and Z. Derriche, "Synthesis of zeolites 4A and HS from natural materials", Annual de Chimie Science des Materiaux, Vol. 27, 2002, pp.1.

[7] X. Querol, N. Moreno, J.C. Umana, A. Alastuey and E. Herna'ndez, "Synthesis of zeolites from coal fly ash: an overview", International Journal of Coal Geology, Vol. 50, 2000, pp. 413.

[8] G. C. C. Yang and T.-. Yang, "Synthesis of zeolites from municipal incinerator fly ash", Journal of Hazardous Materials, Vol. 62, 1998, pp. 75

[9] T. Wajima, K. Kuzawa, H. Ishimoto, O. Tamada and T. Nishiyama, "The synthesis of zeolite-P, Linde type A, and hydroxysodalite zeolites from paper sludge ash at low temperature $(80$ 8C): optimal ash-leaching condition for zeolite synthesis", American Mineralogist, Vol. 89, 2004, pp. 1694.

[10] N. Ay and M. Unal, "The use of waste ceramic tile in cement production", Cement and Concrete Research, Vol. 30, 2000, pp. 497 